\title{
REVIEW
}

\section{A Review of Biologic Therapies Targeting IL-23 and IL-17 for Use in Moderate-to-Severe Plaque Psoriasis}

Molly Campa $\cdot$ Bobbak Mansouri $\cdot$ Richard Warren $\cdot$ Alan Menter (D)

To view enhanced content go to www.dermtherapy-open.com

Received: September 14, 2015 / Published online: December 29, 2015

(C) The Author(s) 2015. This article is published with open access at Springerlink.com

\section{ABSTRACT}

The development of several highly effective biologic drugs in the past decade has revolutionized the treatment of moderate-to-severe plaque psoriasis. With increased understanding of the immunopathogenesis of psoriasis, the emphasis has turned toward more specific targets for psoriasis drugs. Although the complex immunological pathway of psoriasis is not yet completely understood, current models emphasize the significant importance of interleukin (IL)-23 and IL-17. Several biologic drugs targeting these cytokines are now in various stages of drug development. Drugs

Electronic supplementary material The online version of this article (doi:10.1007/s13555-015-0092-3) contains supplementary material, which is available to authorized users.

M. Campa · A. Menter ( $₫)$

Division of Dermatology, Baylor University Medical

Center, Dallas, TX, USA

e-mail: amderm@gmail.com

B. Mansouri

Department of Dermatology, Baylor Scott and

White Medical Center, Temple, TX, USA

R. Warren

University of Manchester, Manchester, UK targeting IL-23 include BI-655066, briakinumab, guselkumab, tildrakizumab, and ustekinumab. Drugs targeting IL-17 include brodalumab, ixekizumab, and secukinumab. While many of these have shown safety and good efficacy in clinical trials of moderate-to-severe plaque psoriasis, long-term safety is still to be established.

Keywords: Biologics;

Interleukin-17; Interleukin-23; Psoriasis

\section{INTRODUCTION}

Psoriasis is a common chronic immune-mediated inflammatory skin disease affecting $0.5-3 \%$ of the world's population, born of the complex interaction of the innate and adaptive immune systems together with a wide array of genetic pathways [1-4]. It is associated with decreased quality of life and multiple comorbid conditions, including the metabolic syndrome and cardiovascular disease $[5,6]$. Plaque psoriasis, the most common variant of psoriasis, is characterized by well-demarcated, erythematous plaques with 
adherent silvery scales [1]. Approximately 1.2 million patients (17\%) in the US with plaque psoriasis have moderate-to-severe disease, often defined as psoriasis covering at least $10 \%$ of the body surface area or causing significant quality of life impairment [4].

Although the pathogenesis of psoriasis is not completely understood, multiple environmental factors, T cells, dendritic cells, numerous cytokines, and 45 identified gene loci all interact to create the systemic psoriatic disease state and ultimately psoriatic plaques $[1,7]$. Affected keratinocytes activate dendritic cells, which then travel to local lymph nodes and release several cytokines including interleukin (IL)-12 and IL-23, which activate type $1 \mathrm{~T}$ helper $\left(\mathrm{T}_{\mathrm{h}} 1\right)$ and type $17 \mathrm{~T}$ helper $\left(\mathrm{T}_{\mathrm{h}} 17\right)$ cells, respectively [8]. T lymphocytes and other cell types release additional cytokines, including tumor necrosis factor (TNF)- $\alpha$, IL-22, and IL-17, leading to increased keratinocyte activation and the initiation of a self-propelled cycle of inflammation [1,9]. Although earlier models focused on $T_{h} 1$ cells as the central cell type for psoriasis pathogenesis, newer models focus on the IL-23/ $\mathrm{T}_{\mathrm{h}} 17$ axis [9]. In this model, IL-17 is secreted by $\mathrm{T}_{\mathrm{h}} 17$ cells and is seen as one of the most important cytokines in psoriasis, while IL-23 drives $\mathrm{T}_{\mathrm{h}} 17$ cell activation [9].

Recent research indicates that both IL-23 and IL-17 play important, and perhaps integral, roles in the development of psoriatic plaques $[8,10,11]$. IL-23 is a pro-inflammatory cytokine produced predominately by inflammatory myeloid cells [12]. IL-23 is heterodimer comprised of a p40 subunit, which it has in common with IL-12, and a p19 subunit unique to IL-23. IL-23 signals via the IL-23R and IL-23R $\beta 1$ receptors [12]. As such, the success of IL-12/23p40 antagonists in treating plaque psoriasis is likely the result of a decrease in IL-23 rather than IL-12, as evidenced by increased IL-12/23p40 and IL23p19 in psoriatic plaques but no corresponding increase in IL-12p35 [9]. IL-23, in the presence of IL-6 and transforming growth factor (TGF)- $\beta$, stimulates the differentiation of $\mathrm{T}$ cells to $\mathrm{T}_{\mathrm{h}} 17$ cells and plays an integral role in the survival of these cells [12-14]. This stimulation of $T_{h} 17$ cells leads to an increase in the release of IL-17 [8].

IL-17 secreting $\mathrm{T}$ cells, including $\mathrm{T}_{\mathrm{h}} 17$ cells and others, play an important role in the regulation of the adaptive and innate immune systems as well as the pathogenesis of psoriasis [8]. The primary cytokines produced by $T_{h} 17$ cells are those of the pro-inflammatory IL-17 family, including IL-17A, IL-17B, IL-17C, IL-17D, IL-17E, and IL-17F [11, 14, 15]. IL-17A and IL-17F are similar and bind to the same IL-17 receptor, a heterodimer comprised of a IL-17RA and a IL-17RC subunits [15]. IL-17A plays an important role in immunologic defense against extracellular pathogens and in the pathogenesis of different immune-mediated diseases, including psoriasis [15]. IL-17 has several different functions including neutrophil recruitment, induction of a $\mathrm{T}_{\mathrm{h}} 2$ response that protects against extracellular organisms, stimulation of macrophages to produce IL- $1 \beta$ and TNF- $\alpha$, and induction of inflammatory mediators such as matrix metalloproteinases (MMPs) [15].

In addition to its production by $\mathrm{T}_{\mathrm{h}} 17$ cells, IL-17 is also produced by $\gamma \delta$ T cells, neutrophils, and mast cells [16]. A small study using immunofluorescence in human skin suggested that mast cells and neutrophils may play a substantial role in the release of IL-17 when compared to $T_{h} 17$ cells, as there are more mast cells and neutrophils producing IL-17 in psoriatic plaques than $\mathrm{T}_{\mathrm{h}} 17$ cells [16]. It has been suggested, with some controversy, that the success of other immune modulating therapies, including cyclosporine and TNF- $\alpha$ antagonists, 
may represent the indirect effects of those therapies on the downstream IL-23/ $\mathrm{T}_{\mathrm{h}} 17$ axis, producing an indirect decrease in IL-17 [10].

In the last three decades, the development of several highly effective biologic drugs has revolutionized the treatment of moderate-to-severe plaque psoriasis. These medications are a reflection of our increased understanding of psoriasis pathogenesis, including the central importance of IL-23, and IL-17. There are five biologic therapies for moderate-to-severe plaque psoriasis currently approved by the US Food and Drug Administration (FDA) and the European Medicines Agency (EMA). These include three TNF- $\alpha$ antagonists (adalimumab, etanercept, and infliximab), one IL-12/23p40 inhibitor (ustekinumab), and a recently approved IL-17A inhibitor (secukinumab). With recent data specifically highlighting the importance of IL-23 and IL-17, the focus has shifted to the development of additional biologic drugs targeting these cytokines [11, 13, 17]. Several additional biologic medications targeting IL-23 and IL-17 are in various phases of clinical development for moderate-to-severe psoriasis. Drugs targeting IL-23 include BI 655066, briakinumab, guselkumab, tildrakizumab, and ustekinumab. Drugs targeting IL-17 include brodalumab, ixekizumab, and secukinumab. Recent technology has been able to incorporate a TNF inhibitory agent together with an IL-17 blocking agent into a single molecule for future therapeutic research potential (see Table 1) [18, 19].

The most common methods for clinical assessment in clinical trials for psoriasis are the Psoriasis Assessment and Severity Index (PASI) score and the Physicians Global Assessment (PGA). The PASI score rates psoriasis on a scale of $0-72$ based on the erythema, induration, and scale of the plaques weighted by body surface area, with higher scores representing more severe disease and a PASI score of 12 representing the minimal score to qualify for clinical trials for moderate-to-severe disease. Clinical trial study endpoints often assess the percentage of patients who achieve a $75 \%$ reduction in PASI score, termed PASI 75 , or a $90 \%$ decrease in PASI, termed PASI 90. A low PASI score at the end of a study may better represent a good response, however, as patients with a lower score at the beginning of the study may be less likely to reach a PASI 90. The PGA is typically a scale from 0 to 5 with 0 representing "Clear" and 5 representing "Severe disease".

\section{METHODS}

The objective of this paper is to provide a concise review of the current biologic therapies for moderate-to-severe plaque psoriasis that target IL-23 and IL-17. A literature review, undertaken by the authors, searched PubMed for articles in English using the following key words: IL-17, IL-23, psoriasis, BI-655066, briakinumab, brodalumab, guselkumab, ixekizumab, secukinumab, tildrakizumab, and ustekinumab. Duplicate articles were removed, and 832 article titles were reviewed. Of these, the abstracts for 403 articles were reviewed. Of these, 234 articles were selected for further review. Our paper focuses on the most recent phases of relevant clinical trials. This was not a systematic review, and not all results can be directly compared to each other, due to differing study specifics, methodology, endpoints, and objectives. This article is based on previously conducted studies, and does not involve any new studies of human or animal subjects performed by any of the authors. 
Table 1 Biologic drugs targeting IL-23 and IL-17

\begin{tabular}{|c|c|c|c|c|}
\hline Drug & Drug company & Drug type & Target & $\begin{array}{l}\text { Current status for } \\
\text { plaque psoriasis }\end{array}$ \\
\hline $\begin{array}{l}\text { Ustekinumab (Stelara }^{\circledR}, \\
\text { CNTO1275) }\end{array}$ & Janssen & $\begin{array}{l}\text { Human monoclonal } \\
\text { antibody }\end{array}$ & $\begin{array}{l}\text { P40 subunit of } \\
\text { IL-23 and IL-12 }\end{array}$ & Approved \\
\hline Briakinumab (ABT 874) & Abbott & $\begin{array}{l}\text { Human monoclonal } \\
\text { antibody }\end{array}$ & $\begin{array}{l}\text { P40 subunit of } \\
\text { IL-23 and IL-12 }\end{array}$ & Terminated \\
\hline $\begin{array}{l}\text { Tildrakizumab } \\
\text { (MK-3222) }\end{array}$ & Merck & $\begin{array}{l}\text { Humanized monoclonal } \\
\text { antibody }\end{array}$ & $\begin{array}{l}\text { p19 subunit of } \\
\text { IL-23 }\end{array}$ & Phase III \\
\hline BI 655066 & $\begin{array}{l}\text { Boehringer } \\
\text { Ingelheim }\end{array}$ & Monoclonal antibody & $\begin{array}{l}\text { p19 subunit of } \\
\text { IL-23 }\end{array}$ & Phase II \\
\hline $\begin{array}{l}\text { Guselkumab (CNTO } \\
\text { 1959) }\end{array}$ & Janssen & $\begin{array}{l}\text { Human IgG1 } \lambda \text { monoclonal } \\
\text { IL-23 antibody }\end{array}$ & $\begin{array}{l}\text { p19 subunit of } \\
\text { IL-23 }\end{array}$ & Phase III \\
\hline $\begin{array}{l}\text { Secukinumab } \\
\quad\left(\text { Cosentyx }{ }^{\circledR}, \text { AIN 457) }\right.\end{array}$ & Novartis & $\begin{array}{l}\text { Human monoclonal } \\
\text { antibody }\end{array}$ & IL-17A & Approved \\
\hline $\begin{array}{l}\text { Ixekizumab } \\
\text { (LY2439821) }\end{array}$ & Eli Lilly & $\begin{array}{l}\text { Humanized monoclonal } \\
\text { antibody }\end{array}$ & IL-17A & Phase III \\
\hline Brodalumab (AMG 827) & $\begin{array}{l}\text { Amgen/ } \\
\text { AstraZeneca/ } \\
\text { Valeant }\end{array}$ & $\begin{array}{l}\text { Human monoclonal } \\
\text { antibody }\end{array}$ & IL-17 receptor A & $\begin{array}{l}\text { No ongoing } \\
\text { studies }\end{array}$ \\
\hline ABT-122 & AbbVie & $\begin{array}{l}\text { Dual variable domain } \\
\text { antibody }\end{array}$ & IL-17 and TNF- $\alpha$ & Phase II \\
\hline
\end{tabular}

$I L$ interleukin, $T N F$ tumor necrosis factor

\section{DRUGS TARGETING THE P40 SUBUNIT OF IL-12 AND IL-23}

\section{Ustekinumab}

Ustekinumab (Stelara ${ }^{\circledR}$; Janssen Biotech, Inc.), a fully human $\operatorname{IgG} 1 / \kappa$ monoclonal antibody that binds to the shared p40 subunit of IL-12 and IL-23, was approved in the US and Europe in 2009 for moderate-to-severe plaque psoriasis in patients who are candidates for phototherapy or systemic therapy [20, 21]. This approval was expanded in 2013 to include the indication psoriatic arthritis [20]. The binding of ustekinumab to the p40 subunit of IL-12 and IL-23 prevents these cytokines from interacting with their shared cell-surface receptor chain, IL-12 $\beta 1$ [20]. Ustekinumab is administered via subcutaneous injection, with patients $\leq 100 \mathrm{~kg}$ receiving $45 \mathrm{mg}$, and those $>100 \mathrm{~kg}$ receiving $90 \mathrm{mg}$. It is dosed at week 0 and week 4, and thereafter every 12 weeks [20].

\section{Clinical Trials}

Based on data from several clinical trials and post-marketing registries, ustekinumab is safe and efficacious in the treatment of moderate-to-severe plaque psoriasis [22-26]. In PHOENIX-1 and PHOENIX-2 (ClinicalTrials.gov identifiers, NCT00267969 and NCT00307437, respectively), two phase III, parallel, double-blind, placebo-controlled studies, 
ustekinumab was effective in treating plaque psoriasis at $45 \mathrm{mg}$ and $90 \mathrm{mg}$ doses given every 12 weeks. PASI 75 was achieved in $66.7-67.1 \%$ of subjects taking a $45 \mathrm{mg}$ dose, $66.4-75.7 \%$ of subjects taking $90 \mathrm{mg}$, and $3.1-3.7 \%$ of those on placebo at 12 weeks $[23,24]$. In a randomized, active comparator study, where investigators were blinded to treatment arms, but subjects were unblinded, ustekinumab at both $45 \mathrm{mg}$ and $90 \mathrm{mg}$ doses at week 0, 4, and every 12 weeks thereafter was shown to be more effective than $50 \mathrm{mg}$ etanercept twice weekly based on the percent of subjects achieving PASI 75 at 12 weeks: $67.5 \%$ on $45 \mathrm{mg}$ ustekinumab, $73.8 \%$ on $90 \mathrm{mg}$ ustekinumab, and $56.8 \%$ on etanercept [25]. Subjects taking ustekinumab were also more likely to have PGA scores of 0 or 1 at week 12: $65.1 \%$ of the $45 \mathrm{mg}$ treatment arm, $70.6 \%$ of the $90 \mathrm{mg}$ treatment arm, and $49.0 \%$ of the etanercept treatment arm [25].

In a phase IV, open-label, parallel-group, randomized clinical trial, patients with inadequate response to methotrexate 10-25 mg weekly (PASI $\geq 10$ ), were randomized to receive ustekinumab ( $45 \mathrm{mg}$ every 12 weeks if $\leq 100 \mathrm{~kg}$, and $90 \mathrm{mg}$ every 12 weeks if $>100 \mathrm{~kg}$ ) with immediate withdrawal of methotrexate or with a 4 week overlapping tapering dose of methotrexate [27]. Efficacy and safety parameters were similar in the two treatment groups [27]. These results were not compared with transitioning to ustekinumab after a washout period.

\section{Other Studies}

A retrospective analysis of over 100 patients taking ustekinumab with a median follow up period of 31 months found that $57 \%$ of patients on ustekinumab monotherapy maintained adequate clearance (defined as PASI 90) at the last available follow up visit [28]. Furthermore, after five continuous years of follow up based on data from two large clinical trial extensions, no increase in adverse events was observed with treatment up to five years, with no positive or negative effects in cardiovascular outcomes [22, 29]. Based on registry data of over 12,000 patients, ustekinumab does not increase the risk of malignancy, major adverse cardiovascular events (MACE), serious infections, or mortality and has been shown by multiple registries (BADBIR, Danish, and PSOLAR) to be the biologic agent least likely to be discontinued $[26,30,31]$.

\section{Briakinumab}

Briakinumab (ABT-874; Abbott Laboratories) was another fully human monoclonal antibody specific for the shared p40 subunit of IL-12 and IL-23. In 2011, after phase III trials, Abbott Laboratories discontinued all clinical trials and withdrew their application for approval after concern of a possible increased risk for MACE, defined as myocardial infarction, cerebrovascular accident, and cardiac death [32]. There are no clinical trials currently ongoing relating to this drug.

\section{Clinical Trials}

Before its development was discontinued, briakinumab showed significant promise in phase III trials [33]. In a randomized, double-blind, placebo-controlled study, 80.7\% of subjects receiving briakinumab achieved PASI 75 at 12 weeks, compared to $4.5 \%$ of patients on placebo [33]. In this same study, subjects were randomized to receive $100 \mathrm{mg}$ every 4 or every 12 weeks. At 52 weeks, $79.2 \%$ of those receiving $100 \mathrm{mg}$ every 4 weeks achieved a PGA of 0 or 1 , and $41.6 \%$ of those receiving $100 \mathrm{mg}$ every 12 weeks achieved a PGA of 0 or 1 . Serious infections (five versus one event on briakinumab and placebo, respectively), 
non-melanoma skin cancers (ten versus zero events), and MACE (seven versus zero events) were more common in those on briakinumab than placebo. A statistically significant $p$ value was not reported for any of these data points [33].

In two separate 12 week phase III, randomized, placebo-controlled studies, briakinumab (200 $\mathrm{mg}$ at week 0 and 4 followed by $100 \mathrm{mg}$ at week 8 ) was shown to have superior efficacy compared to etanercept (50 mg twice weekly) and placebo: PGA 0/1: 70.1-72.7\% briakinumab, 29.5-39.7\% etanercept, and $2.9-4.2 \%$ placebo; PASI 75 : 80.6-81.9\% briakinumab, 39.6-56.0\% etanercept, and $6.9-7.4 \%$ placebo $[34,35]$.

When compared to methotrexate, briakinumab was more effective with a faster onset of efficacy [36]. In a 24-week, randomized, double-blind study with a 52-week open-label extension, subjects were randomized 1:1 to receive methotrexate $(5 \mathrm{mg}$ weekly titrated up to $25 \mathrm{mg}$ weekly in subjects not reaching PASI 75 ) or briakinumab $200 \mathrm{mg}$ at week 0 and 4 , and $100 \mathrm{mg}$ every 4 weeks thereafter. At week 24, PASI 75 was achieved in $81.8 \%$ of subjects on briakinumab and $39.9 \%$ of subjects on methotrexate. At week 52, 66.2\% of subjects on briakinumab and $23.9 \%$ of subjects on methotrexate maintained a PASI 75 response [36]. A PGA of 0 or 1 was achieved at week 24 in $80.5 \%$ of briakinumab subjects and $34.4 \%$ methotrexate subjects, and was maintained at 52 weeks in $63.0 \%$ briakinumab subjects and $20.2 \%$ methotrexate subjects [36]. Serious adverse events were reported in $9.1 \%$ of subjects in the briakinumab arm and $6.1 \%$ of subjects in the methotrexate arm, but this difference was not statistically significant [36].

\section{DRUGS TARGETING THE P19 SUBUNIT OF IL-23}

\section{Tildrakizumab}

Tildrakizumab (MK-3222, Merck \& Co.) is a

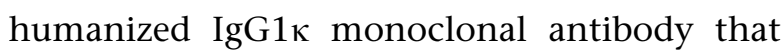
targets the unique p19 subunit of IL-23 [37]. It has no affinity for IL-12.

\section{Clinical Trials}

A randomized, double-blind, phase IIb clinical trial revealed that tildrakizumab was effective in treating moderate-to-severe plaque psoriasis. Each participant was randomized to receive tildrakizumab $(5,25,100$, or $200 \mathrm{mg})$ or placebo via subcutaneous injection every 12 weeks after two initial doses at weeks 0 and 4 [37]. At week 16, the proportion of subjects achieving PASI 75 was significantly higher at all doses when compared to placebo: $33.3 \%$ on $5 \mathrm{mg}, 64.4 \%$ on $25 \mathrm{mg}, 66.3 \%$ on $100 \mathrm{mg}$, and $74.4 \%$ on $200 \mathrm{mg}$, compared to $4.4 \%$ on placebo [37]. The final drug dose was given on week 40, and the participants were followed until week 72. Tildrakizumab demonstrated a low rate of relapse after cessation of therapy, with only $3.6 \%$ of the participants who achieved PASI 75 at week 52 on any dose of tildrakizumab relapsing before week 72 [37]. Phase III studies are in progress [38, 39].

\section{BI-655066}

BI-655066 (Boehringer Ingelheim) is a high affinity monoclonal antibody targeting the p19 subunit of IL-23 and is currently in development for moderate-to-severe psoriasis and Crohn's disease. 


\section{Clinical Trials}

A phase I, proof-of-concept study of BI-655066 demonstrated a similar frequency of side effects with varying doses of BI-655066 compared to placebo [40]. The most common side effects were mild-to-moderate upper respiratory infections, mild nasopharyngitis, and mild-to-moderate headache [40]. After a single intravenous or subcutaneous dose, PASI 75 was achieved in $87 \%$ of subjects, PASI 90 in $58 \%$ of subjects, and PASI 100 in $16 \%$ of subjects [40]. Phase II trials have been completed, and publication of results is pending. Additional trials are ongoing [41].

\section{Guselkumab}

Guselkumab (CNTO 1959, Janssen Research and Development) is a fully human IgG1 $\lambda$ monoclonal IL-23 antagonist targeting the unique p19 subunit of IL-23 [42].

\section{Clinical Trials}

In a phase II, randomized, double-blind, placebo-controlled, dose-ranging, active-comparator study, patients randomized to guselkumab were significantly more likely to achieve a PGA score of 0 (clear) or 1 (almost clear) at 16 weeks when compared to placebo: $34 \%$ in the $5 \mathrm{mg}$ dose group, $61 \%$ in the $15 \mathrm{mg}$ dose group, $79 \%$ in the $50 \mathrm{mg}$ dose group, $86 \%$ in the $100 \mathrm{mg}$ dose group, $83 \%$ in the $200 \mathrm{mg}$ dose group, and $7 \%$ in the placebo group. At 16 weeks, a score of 0 or 1 on the PGA was seen in $58 \%$ of patients randomized to adalimumab, which was significantly lower than the 50, 100, and $200 \mathrm{mg}$ doses of guselkumab [42]. PASI 75 at 16 weeks was significantly higher in those taking all doses of guselkumab compared to placebo: $44 \%$ in the $5 \mathrm{mg}$ dose group, $76 \%$ in the $15 \mathrm{mg}$ dose group, $81 \%$ in the $50 \mathrm{mg}$ dose group, $79 \%$ in the $100 \mathrm{mg}$ dose group, $81 \%$ in the $200 \mathrm{mg}$ dose group, and 5\% in the placebo group. Seventy percent of patients treated with adalimumab achieved PASI 75, and the statistical significance of this compared to guselkumab was not reported [42]. In this study, efficacy was demonstrated with guselkumab as early as 4 weeks after the first dose [42]. Larger, phase III trials are currently underway [43-45].

\section{DRUGS TARGETING IL-17}

\section{Secukinumab}

Secukinumab (Cosentyx ${ }^{\circledR}$, Novartis Pharma AG) is a fully human anti-IL-17A IgG1 $\kappa$ monoclonal antibody [46]. In 2015, it was approved in the US and in Europe as a first line drug for the treatment of moderate-to-severe plaque psoriasis [21, 47]. Cosentyx is administered subcutaneously with a $300 \mathrm{mg}$ dose at weeks 0 , $1,2,3,4$, and every 4 weeks thereafter [47]. A $150 \mathrm{mg}$ dose is also approved for use [47]. Although many of the biologic drugs approved for psoriasis are also approved for Crohn's disease, in a randomized, double-blind, placebo-controlled, proof of concept study, secukinumab was ineffective in treating Crohn's disease and was associated with increased side effects [48].

\section{Clinical Trials}

In two phase III, double-blind 52-week trials for moderate-to-severe plaque psoriasis, secukinumab demonstrated a PASI 75 in $67.0-71.6 \%$ of patients with a $150-\mathrm{mg}$ dose and $77.1-81.6 \%$ of patients with $300 \mathrm{mg}$ dose; both superior to the $4.5-4.9 \%$ of patients achieving PASI 75 on placebo [46]. These results were also superior to the $44 \%$ of patients on $50 \mathrm{mg}$ etanercept twice weekly for 
12 weeks then weekly thereafter that achieved a PASI 75 [46]. Patients achieved a PGA score of 0 (clear) or 1 (almost clear) at 12 weeks in $51.1-51.2 \%$ of patients taking $150 \mathrm{mg}$ and $62.5-65.3 \%$ of patients taking $300 \mathrm{mg}, 27.2 \%$ of patients on a $50 \mathrm{mg}$ etanercept twice weekly, and $2.4-2.8 \%$ of patients on placebo [46]. In the FEATURE study (ClinicalTrials.gov identifier, NCT01555125), a 12-week randomized, double-blind, placebo-controlled, parallel group phase III trial $75.9 \%$ of subjects on $300 \mathrm{mg}$ secukinumab, $69.5 \%$ of subjects on $150 \mathrm{mg}$ secukinumab, and $0 \%$ of subjects on placebo achieved PASI 75 at week 12 [49]. In the same study, $69.0 \%$ of subjects on $300 \mathrm{mg}$, $52.5 \%$ of subjects on $150 \mathrm{mg}$, and $0 \%$ of subjects on placebo achieved a score of 0 or 1 on the 2011 modified Investigator's Global Assessment [49]. This study also reported high usability of a prefilled syringe with a safety profile similar to previous studies [49].

A study comparing retreatment-as-needed secukinumab versus fixed-interval secukinumab was unable to show a statistically significant difference between the two dosing methods, although the rates of those achieving and maintaining PASI 75 were numerically higher in the fixed-interval group [50]. The most common side effects associated with this drug are nasopharyngitis, headache, and upper respiratory infections, which are similar to other biologic drugs [46].

In the CLEAR study (ClinicalTrials.gov identifier, NCT02074982), a randomized controlled trial comparing secukinumab to ustekinumab, secukinumab showed superior efficacy, with $79.0 \%$ of subjects and $57.6 \%$ of subjects reaching PASI 90 at 16 weeks in the secukinumab and ustekinumab groups, respectively [51]. Additionally, PASI 100 (complete clearance) at 16 weeks was achieved by a significantly higher proportion of subjects receiving secukinumab versus ustekinumab: $44.3 \%$ compared to $28.4 \%$ [51].

\section{Ixekizumab}

Ixekizumab (Eli Lily) is a monoclonal antibody specific for IL-17A.

\section{Clinical Trials}

Two phase III studies for moderate-to-severe plaque psoriasis with $80 \mathrm{mg}$ doses given every 2 or 4 weeks show a $77.5-89.7 \%$ achievement of PASI 75 at 12 weeks, which is significantly higher than the $41.6-53.4 \%$ of patients achieving PASI 75 on the active comparator, etanercept (50 mg twice weekly) [52]. Additionally, $30.8-40.5 \%$ of the patients achieved PASI 100 (complete clearance) at 12 weeks [52]. High levels of response were maintained through 60 weeks of treatment [52]. The most common adverse events seen in these trials were nasopharyngitis and injection site reactions, with rates and severity comparable to etanercept [52]. Additional studies are ongoing.

\section{DRUGS TARGETING IL17RA}

\section{Brodalumab}

Brodalumab (AstraZeneca) is unique among the biologic drugs targeting IL-17, as it is a fully human monoclonal antibody targeting the IL-17 receptor A (IL-17RA) rather than the IL-17A cytokine itself [53]. It inhibits binding of several members of the IL-17 cytokine family, including IL-17A and IL-17F, to the receptor [53]. In May 2015, Amgen announced that it would no longer be co-developing and commercializing brodalumab with AstraZeneca due to concerns over increased suicidal ideation and behavior [54]. In September 2015, AstraZeneca stated that 
it will partner with Valeant Pharmaceuticals International Inc. for further development and commercialization of brodalumab, and Valeant will submit EU and US regulatory filings in the fourth quarter of 2015 [55].

\section{Clinical Trials}

Before Amgen terminated its development and commercialization, brodalumab was undergoing phase III trials for moderate-to-severe plaque psoriasis, as well as clinical trials for psoriatic arthritis and axial spondyloarthritis [54]. Brodalumab showed promising results at 12 and 120 weeks in a phase II, randomized, double-blind, placebo-controlled study with an open-label extension period. At 12 weeks, 95\% subjects achieved a PASI $75,85 \%$ achieved PASI 90 , and $63 \%$ achieved PASI 100. At 120 weeks 86\% maintained PASI 75, 70\% maintained PASI 90, and 51\% maintained a PASI 100 [56]. A subset analysis of the phase II data revealed similar efficacy and patient reported outcomes despite co-existence of psoriatic arthritis or prior biologic use [57]. Three randomized, placebo-controlled phase III studies, AMAGINE-1 ${ }^{\mathrm{TM}}$, AMAGINE-2 ${ }^{\mathrm{TM}}$, and AMAGINE-3 ${ }^{\mathrm{TM}}$ (ClinicalTrials.gov identifiers, NCT01708590, NCT01708603, and NCT01708629, respectively), were underway at the time that Amgen announced that it would no longer be pursuing development of brodalumab. Together these studies found the following rates of PASI 75 achievement at 12 weeks: $83-86 \%$ of subjects on $210 \mathrm{mg}, 60-69 \%$ on $140 \mathrm{mg}, 3-8 \%$ on placebo, and $69-70 \%$ on the active comparator ustekinumab [58-60]. Additionally, brodalumab at both doses was numerically superior to ustekinumab in achieving complete clearance (PASI 100), but statistical significance of this difference was not consistently achieved: $37-44 \%$ in $210 \mathrm{mg}$ dose, $26-27 \%$ in $140 \mathrm{mg}$ dose, $0.3-1 \%$ in placebo, and $19-22 \%$ in ustekinumab [60].

\section{CONCLUSIONS}

Both IL-23 and IL-17 are promising targets in the treatment of moderate-to-severe plaque psoriasis. Biologic drugs targeting these cytokines and their receptors have proven to be effective and safe in clinical trials and have offered greater efficacy than pre-existing biologics, as evidenced by large proportions of patients achieving not only PASI 75 but also PASI 90 and PASI 100. It is important to be vigilant in following the safety profile of these drugs both in clinical trials and in post-marketing registries to ensure their long-term safety.

\section{ACKNOWLEDGMENTS}

No funding or sponsorship was received for publication of this article. All named authors meet the International Committee of Medical Journal Editors (ICMJE) criteria for authorship for this manuscript, take responsibility for the integrity of the work as a whole, and have given final approval for the version to be published.

Disclosures. M. Campa has no conflicts of interest. B. Mansouri has received an honorarium and has sat on an advisory board for Celgene. R. Warren has been a speaker and/ or consultant for AbbVie, Amgen, Boehringer Ingelheim, Eli Lilly and Company, Janssen Pharmaceuticals, Leo Pharma, Novartis, Pfizer, Inc., and Xenoport. A. Menter has been an advisor, consultant, and/or speaker for AbbVie, Allergan, Amgen Inc., Boehringer Ingelheim, Celgene, Convoy Therapeutics, Inc., Eli Lilly and Company, Genetech, Janssen Pharmaceuticals, BioTech, Inc., Leo Pharma, Novartis, Pfizer, Inc., Syntrix, Wyeth, and Xenoport. The authors have no other relevant affiliations or financial involvement with any 
organization or entity with a financial interest in or financial conflict with the subject matter or materials discussed in the manuscript apart from those disclosed.

Compliance with Ethics Guidelines. This article is based on previously conducted studies, and does not involve any new studies of human or animal subjects performed by any of the authors.

Open Access. This article is distributed under the terms of the Creative Commons Attribution-NonCommercial 4.0 International License (http://creativecommons.org/licenses/ by-nc/4.0/), which permits any noncommercial use, distribution, and reproduction in any medium, provided you give appropriate credit to the original author(s) and the source, provide a link to the Creative Commons license, and indicate if changes were made.

\section{REFERENCES}

1. Nestle FO, Kaplan DH, Barker J. Psoriasis. N Engl J Med. 2009;361(5):496-509.

2. Bos JD, De Rie MA. The pathogenesis of psoriasis: immunological facts and speculations. Immunol Today. 1999;20(1):40-6.

3. Christophers E. Psoriasis-epidemiology and clinical spectrum. Clin Exp Dermatol. 2001;26(4):314-20.

4. Kurd SK, Gelfand JM. The prevalence of previously diagnosed and undiagnosed psoriasis in US adults: results from NHANES 2003-2004. J Am Acad Dermatol. 2009;60(2):218-24.

5. Koo J. Population-based epidemiologic study of psoriasis with emphasis on quality of life assessment. Dermatol Clin. 1996;14(3):485-96.

6. Villasenor-Park J, Wheeler D, Grandinetti L. Psoriasis: evolving treatment for a complex disease. Cleve Clin J Med. 2012;79(6):413-23.
7. Mahil SK, Capon F, Barker JN. Genetics of psoriasis. Dermatol Clin. 2015;33(1):1-11.

8. Sharma J, Balakrishnan L, Datta KK, et al. A knowledgebase resource for interleukin-17 family mediated signaling. J Cell Commun Signal. 2015;9(3):291-6.

9. Lowes MA, Russell CB, Martin DA, Towne JE, Krueger JG. The IL-23/T17 pathogenic axis in psoriasis is amplified by keratinocyte responses. Trends Immunol. 2013;34(4):174-81.

10. Chandrakumar SF, Yeung J. Interleukin-17 antagonists in the treatment of psoriasis. J Cutan Med Surg. 2015;19(2):109-14.

11. Grine L, Dejager L, Libert C, Vandenbroucke RE. An inflammatory triangle in psoriasis: TNF, type I IFNs and IL-17. Cytokine Growth Factor Rev. 2015;26(1):25-33.

12. Teng MW, Bowman EP, McElwee JJ, et al. IL-12 and IL-23 cytokines: from discovery to targeted therapies for immune-mediated inflammatory diseases. Nat Med. 2015;21(7):719-29.

13. Malakouti M, Brown GE, Wang E, Koo J, Levin EC. The role of IL-17 in psoriasis. J Dermatol Treat. 2015;26(1):41-4.

14. Volpe E, Servant N, Zollinger R, et al. A critical function for transforming growth factor-beta, interleukin 23 and proinflammatory cytokines in driving and modulating human $\mathrm{T}(\mathrm{H})-17$ responses. Nat Immunol. 2008;9(6):650-7.

15. Isailovic $\mathrm{N}$, Daigo $\mathrm{K}$, Mantovani A, Selmi C. Interleukin-17 and innate immunity in infections and chronic inflammation. $\mathrm{J}$ Autoimmun. 2015;60:1-11.

16. Lin AM, Rubin CJ, Khandpur R, et al. Mast cells and neutrophils release IL-17 through extracellular trap formation in psoriasis. J Immunol (Baltimore, Md: 1950). 2011;187(1):490-500.

17. Ratner M. IL-17-targeting biologics aim to become standard of care in psoriasis. Nat Biotechnol. 2015;33(1):3-4.

18. Mansikka H RM, Hugunin M, Ivanov A, Brito A, Clabbers A, Cuff C, Hsieh CM, Okun M, Heuser R, Carter D, Hendrickson B, Pisal D, Goss S, Liu J, Locke C, Khan N, Padley R. Safety, tolerability, and functional activity of ABT-122, a dual TNF- and IL-17A-targeted DVD-Ig ${ }^{\mathrm{TM}}$, following single-dose administration in healthy subjects. Boston: American College of Rheumatology 2014 Annual Meeting; 2014. 
19. Clincal Trial NCT02349451. http://apps.who.int/ trialsearch/Trial2.aspx?TrialID=NCT02349451. Accessed 1 June 2015.

20. Stelara ${ }^{\circledR}$ (ustekinumab) [prescribing information]. Beerse, Belgium: Janssen Biotech; 2009. http://www. accessdata.fda.gov/drugsatfda_docs/label/2009/1252 61lbl.pdf. Accessed 12 Aug 2015.

21. European Public Assessments Reports. http://www. ema.europa.eu/ema/index.jsp?curl=pages\%2Fmedi cines\%2Flanding\%2Fepar_search.jsp\&mid=WC0b01 ac058001d124\&searchTab $=\&$ alreadyLoaded $=$ true $\&$ isNewQuery=true\&status=Authorised\&keyword=En ter+keywords\&searchType=name\&taxonomyPath= Diseases.Skin+and+Connective+Tissue+Diseases. Skin+Diseases.Skin+Diseases\%2C+Papulosquamous \&treeNumber $=\&$ currentCategory=Psoriasis \&search GenericType=generics. Accessed 8 Sept 2015.

22. Papp KA, Griffiths CE, Gordon K, et al. Long-term safety of ustekinumab in patients with moderate-to-severe psoriasis: final results from 5 years of follow-up. $\mathrm{Br} \mathrm{J}$ Dermatol. 2013;168(4):844-54.

23. Leonardi CL, Kimball AB, Papp KA, et al. Efficacy and safety of ustekinumab, a human interleukin-12/23 monoclonal antibody, in patients with psoriasis: 76-week results from a randomised, double-blind, placebo-controlled trial (PHOENIX 1). Lancet. 2008;371(9625):1665-74.

24. Papp KA, Langley RG, Lebwohl M, et al. Efficacy and safety of ustekinumab, a human interleukin-12/23 monoclonal antibody, in patients with psoriasis: 52-week results from a randomised, double-blind, placebo-controlled trial (PHOENIX 2). Lancet. 2008;371(9625):1675-84.

25. Griffiths CE, Strober BE, van de Kerkhof $P$, et al. Comparison of ustekinumab and etanercept for moderate-to-severe psoriasis. $\mathrm{N}$ Engl J Med. 2010;362(2):118-28.

26. Papp K, Gottlieb AB, Naldi L, et al. Safety surveillance for ustekinumab and other psoriasis treatments from the psoriasis longitudinal assessment and registry (PSOLAR). J Drugs Dermatol. 2015;14(7):706-14.

27. Paul C, Puig L, Kragballe K, et al. Transition to ustekinumab in patients with moderate-to-severe psoriasis and inadequate response to methotrexate: a randomized clinical trial (TRANSIT). $\mathrm{Br} \mathrm{J}$ Dermatol. 2014;170(2):425-34.

28. Wilder EG, Patel $M$, Hebeler $K$, Menter A. Ustekinumab treatment for psoriasis in 119 patients maintained on therapy for a minimum of one year: a review. J Drugs Dermatol. 2014;13(8):905-10.
29. Sorenson E, Koo J. Evidence-based adverse effects of biologic agents in the treatment of moderate-to-severe psoriasis: providing clarity to an opaque topic. J Dermatol Treat. 2015;26(6):493-501.

30. Warren RB, Smith CH, Yiu ZZ, et al. Differential drug survival of biologic therapies for the treatment of psoriasis: a prospective observational cohort study from the British Association of Dermatologists Biologic Interventions Register (BADBIR). J Invest Dermatol. 2015;135(11):2632-40.

31. Gniadecki R, Bang B, Bryld LE, et al. Comparison of long-term drug survival and safety of biologic agents in patients with psoriasis vulgaris. $\mathrm{Br} \mathrm{J}$ Dermatol. 2015;172(1):244-52.

32. Ryan C, Leonardi CL, Krueger JG, et al. Association between biologic therapies for chronic plaque psoriasis and cardiovascular events: a meta-analysis of randomized controlled trials. JAMA. 2011;306(8):864-71.

33. Gordon $\mathrm{KB}$, Langley RG, Gottlieb AB, et al. A phase III, randomized, controlled trial of the fully human IL-12/23 mAb briakinumab in moderate-to-severe psoriasis. J Invest Dermatol. 2012;132(2):304-14.

34. Strober BE, Crowley JJ, Yamauchi PS, Olds M, Williams DA. Efficacy and safety results from a phase III, randomized controlled trial comparing the safety and efficacy of briakinumab with etanercept and placebo in patients with moderate to severe chronic plaque psoriasis. Br J Dermatol. 2011;165(3):661-8.

35. Gottlieb AB, Leonardi C, Kerdel F, et al. Efficacy and safety of briakinumab vs. etanercept and placebo in patients with moderate to severe chronic plaque psoriasis. Br J Dermatol. 2011;165(3):652-60.

36. Reich K, Langley RG, Papp KA, et al. A 52-week trial comparing briakinumab with methotrexate in patients with psoriasis. $\mathrm{N}$ Engl J Med. 2011;365(17):1586-96.

37. Papp K, Thaci D, Reich $\mathrm{K}$, et al. Tildrakizumab (MK-3222), an Anti- IL-23p19 Monoclonal Antibody, Improves Psoriasis in a Phase $2 \mathrm{~b}$ Randomized Placebo- Controlled Trial. $\mathrm{Br} J$ Dermatol. 2015;173(4):930-9.

38. Clinical Trial NCT01729754. https://www. clinicaltrials.gov/ct2/show/NCT01729754. Accessed 11 Sept 2015.

39. Clinical Trial NCT01722331. https://www. clinicaltrials.gov/ct2/show/NCT01722331. Accessed 11 Sept 2015.

40. Krueger JG, Ferris LK, Menter A, et al. Anti-IL-23A $\mathrm{mAb} \mathrm{BI} 655066$ for treatment of moderate-to-severe 
psoriasis: Safety, efficacy, pharmacokinetics, and biomarker results of a single-rising-dose, randomized, double-blind, placebo-controlled trial. J Allergy Clin Immunol. 2015;136(1):116-24 e7.

41. Singh S, Kroe-Barrett RR, Canada KA, et al. Selective targeting of the IL23 pathway: Generation and characterization of a novel high-affinity humanized anti-IL23A antibody. mAbs. 2015;7(4):778-91.

42. Gordon KB, Duffin KC, Bissonnette R, et al. A phase 2 trial of guselkumab versus adalimumab for plaque psoriasis. N Engl J Med. 2015;373(2):136-44.

43. A study of guselkumab in the treatment of participants with moderate to severe plaque-type psoriasis with randomized withdrawal and retreatment (VOYAGE 2), NCT02207244. https:// www.clinicaltrials.gov/ct2/show/NCT02207244. Accessed 22 Aug 2015.

44. A study of guselkumab in the treatment of participants with moderate to severe plaque-type psoraisis (VOYAGE 1), NCT02207231. https://www. clinicaltrials.gov/ct2/show/NCT02207231. Accessed 22 Aug 2015.

45. A study of guselkumab in participants with moderate to severe plaque-type psoriasis and an inadequate response to ustekinumab (NAVIGATE), NCT02203032. https://www.clinicaltrials.gov/ct2/ show/NCT02203032. Accessed 22 Aug 2015.

46. Langley RG, Elewski BE, Lebwohl $M$, et al. Secukinumab in plaque psoriasis-results of two phase 3 trials. N Engl J Med. 2014;371(4):326-38.

47. Cosentyx ${ }^{\mathrm{TM}} \quad$ (secukinumab) [prescribing information]. Basel SN. http://www.pharma.us. novartis.com/product/pi/pdf/cosentyx.pdf. Accessed 2 Sept 2015.

48. Hueber W, Sands BE, Lewitzky $S$, et al. Secukinumab, a human anti-IL-17A monoclonal antibody, for moderate to severe Crohn's disease: unexpected results of a randomised, double-blind placebo-controlled trial. Gut. 2012;61(12):1693-700.

49. Blauvelt A, Prinz JC, Gottlieb AB, et al. Secukinumab administration by pre-filled syringe: efficacy, safety and usability results from a randomized controlled trial in psoriasis (FEATURE). Br J Dermatol. 2015;172(2):484-93.

50. Mrowietz U, Leonardi CL, Girolomoni G, et al. Secukinumab retreatment-as-needed versus fixed-interval maintenance regimen for moderate to severe plaque psoriasis: A randomized, double-blind, noninferiority trial (SCULPTURE). J Am Acad Dermatol. 2015;73(1):27-36 e1.

51. Thaci D, Blauvelt A, Reich K, et al. Secukinumab is superior to ustekinumab in clearing skin of subjects with moderate to severe plaque psoriasis: CLEAR, a randomized controlled trial. J Am Acad Dermatol. 2015;73(3):400-9.

52. Griffiths CE, Reich $\mathrm{K}$, Lebwohl M, et al. Comparison of ixekizumab with etanercept or placebo in moderate-to-severe psoriasis (UNCOVER-2 and UNCOVER-3): results from two phase 3 randomised trials. Lancet. 2015;386(9993):541-51.

53. Papp KA, Leonardi C, Menter A, et al. Brodalumab, an anti-interleukin-17-receptor antibody for psoriasis. N Engl J Med. 2012;366(13):1181-9.

54. Amgen to terminate participation in co-development and commercialization of brodalumab [press release]. Thousand Oaks, California: PRNewswire; 22 May 2015.

55. AstraZeneca and Valeant Pharmaceuticals to partner on brodalumab [press release]; 1 September 2015.

56. Papp K, Leonardi C, Menter A, et al. Safety and efficacy of brodalumab for psoriasis after 120 weeks of treatment. J Am Acad Dermatol. 2014;71(6):1183-90 e3.

57. Papp K, Menter A, Strober B, et al. Efficacy and safety of brodalumab in subpopulations of patients with difficult-to-treat moderate-to-severe plaque psoriasis. J Am Acad Dermatol. 2015;72(3):436-9 e1.

58. Papp K RK, Leonardi C, Paul C, Blauvelt A, Baran W, Bolduc C, Toth D, Langley RG, Cather J, Gottlieb A, Thaci D, Milmont CE, Li J, Klekotka P, Kricorian G, Nirula A. Efficacy and safety of brodalumab in patients with moderate to severe plaque psoriasis: Results of AMAGINE-1, a phase 3, randomized, double-blind, placebo-controlled study through week 12. San Francisco, CA: American Academy of Dermatology Annual Meeting; 20-24 March; 2015.

59. Amgen and AstraZeneca announce positive results from Phase III study of brodalumab (AMG 827) in patients with moderate-to-severe plaque psoriasis [press release]. AstraZenca Global; 9 May 2014.

60. Lebwohl M, Strober B, Menter A, et al. Phase 3 studies comparing brodalumab with ustekinumab in psoriasis. N Engl J Med. 2015;373(14):1318-28. 